\title{
Plasma oxalate and eGFR are correlated in primary hyperoxaluria patients with maintained kidney function-data from three placebo-controlled studies
}

\author{
Dawn S. Milliner ${ }^{1} \cdot$ Pierre Cochat $^{2} \cdot$ Sally-Anne Hulton ${ }^{3} \cdot$ Jerome Harambat $^{4} \cdot$ Ana Banos $^{5} \cdot$ Bastian Dehmel $^{5}$. \\ Elisabeth Lindner ${ }^{5}$
}

Received: 24 July 2020 / Revised: 6 November 2020 / Accepted: 3 December 2020 / Published online: 30 January 2021

(C) The Author(s) 2021

\begin{abstract}
Background In patients with primary hyperoxaluria (PH), endogenous oxalate overproduction increases urinary oxalate excretion, leading to compromised kidney function and often kidney failure. Highly elevated plasma oxalate (Pox) is associated with systemic oxalate deposition in patients with PH and severe chronic kidney disease (CKD). The relationship between Pox and estimated glomerular filtration rate (eGFR) in patients with preserved kidney function, however, is not well established. Our analysis aimed to investigate a potential correlation between these parameters in $\mathrm{PH}$ patients from three randomized, placebocontrolled trials (studies OC3-DB-01, OC3-DB-02, and OC5-DB-01).

Methods Baseline data from patients with a PH diagnosis (type 1, 2, or 3) and eGFR > $40 \mathrm{~mL} / \mathrm{min} / 1.73 \mathrm{~m}{ }^{2}$ were analyzed for a correlation between eGFR and Pox using Spearman's rank and Pearson's correlation coefficients. Data were analyzed by individual study and additionally were pooled for Studies OC3-DB-02 and OC5-DB-01 in which the same Pox assay was used. Results A total of 106 patients were analyzed. A statistically significant inverse Spearman's correlation between eGFR and Pox was observed across all analyses; correlation coefficients were -0.44 in study OC3-DB-01, -0.55 in study OC3-DB-02, -0.51 in study OC5-DB-01, and -0.49 in the pooled studies $(p<0.0064)$.

Conclusions Baseline evaluations showed a moderate and statistically significant inverse correlation between eGFR and Pox in patients with PH already at early stages of CKD (stages 1-3b), demonstrating that a correlation is present before substantial loss in kidney function occurs.
\end{abstract}

Keywords Primary hyperoxaluria $\cdot$ Plasma oxalate $\cdot$ eGFR $\cdot$ Chronic kidney disease $\cdot$ Correlation $\cdot$ Clinical trials

Dawn S. Milliner

milliner.dawn@mayo.edu

1 Division of Nephrology, Mayo Clinic, 200 First St. SW, Rochester, MN 55905, USA

2 Centre de Référence des Maladies Rares Néphrogones, Hospices Civils de Lyon \& Université Claude-Bernard Lyon, Lyon, France

3 Birmingham Women's and Children's Hospital NHS Trust, Birmingham, UK

4 Department of Pediatrics, Bordeaux University Hospital, Bordeaux, France

5 OxThera Intellectual Property AB, Stockholm, Sweden

\section{Introduction}

Primary hyperoxalurias (PHs) are a group of rare genetic disorders caused by a range of defects in hepatic glyoxylate metabolic processes. Although the three identified forms of $\mathrm{PH}$ (PH1, PH2 and PH3) are associated with mutations in different genes ( $A G X T, G R H P R$, and $H O G A 1$, respectively), all are characterized by endogenous overproduction of oxalate, a byproduct of normal human metabolism that has low solubility [1-4]. Humans lack the enzymes required to metabolize oxalate, therefore it is excreted primarily via the kidneys in urine [5]. Patients with PH excrete high concentrations of oxalate in the urine, leading to formation of calcium oxalate $(\mathrm{CaOx})$, which precipitates as crystals when urinary supersaturation occurs. Deposits of $\mathrm{CaOx}$ in the tubular lumen and renal parenchyma can result in nephrocalcinosis and urolithiasis. Internalization of $\mathrm{CaOx}$ crystals leads to inflammation, 
decreased kidney function, and often kidney failure [2, 6-8]. In chronic kidney disease (CKD) stages $3 \mathrm{~b}-4$, plasma oxalate (Pox) levels increase dramatically, ultimately depositing $\mathrm{CaOx}$ systemically in organ systems throughout the body in a potentially life-threatening process known as systemic oxalosis $[9,10]$. Once kidney failure occurs, intensive dialysis regimens and eventually kidney transplantation, often in combination with a liver transplantation, are required. The most severe form of $\mathrm{PH}$, type 1 , accounts for approximately $80 \%$ of cases $[1,11,12]$.

Identification of robust endpoints for clinical trials is crucial to permit earlier diagnosis and treatment of patients with $\mathrm{PH}$ before the more severe complications of the disease arise. Surrogate endpoints in clinical trials do not directly measure the clinical benefit of the treatment in question; rather, they can be useful as predictors of treatment efficacy, often by using biomarkers such as laboratory measurements or physical signs [10], which could be tied to a clinical benefit.

Given the rarity of the disease [1], recruitment of patients with $\mathrm{PH}$ to clinical trials is difficult and current treatment options are limited. In patients with $\mathrm{PH}$ and advanced $\mathrm{CKD}$ (stages 3b-5; estimated glomerular filtration rate $(\mathrm{eGFR})<$ $45 \mathrm{~mL} / \mathrm{min} / 1.73 \mathrm{~m}^{2}$ ), highly elevated Pox is directly related to the pathophysiology of oxalosis, and substantial change in Pox may be used as a surrogate endpoint in a clinical setting [10]. There are, however, discrepancies in the literature regarding the relationship of Pox and eGFR in patients with earlier stages of CKD. Data from a recent study indicated that there is a relationship between Pox and eGFR even for patients with less advanced stages of CKD (stages 1-3; mean eGFR at baseline $111 \mathrm{~mL} / \mathrm{min} / 1.73 \mathrm{~m}^{2}$ ) [13]. In a registry of mostly US patients with $\mathrm{PH}$, a clear inverse correlation between Pox and eGFR across a broad range of kidney function was observed [14]. Conversely, in a recent analysis of PH1 patients with stable kidney function from a European registry, no significant correlation between Pox and eGFR was detected [15].

In order to gain a better understanding of the potential association between Pox and eGFR in patients with PH and eGFR $>40 \mathrm{~mL} / \mathrm{min} / 1.73 \mathrm{~m}^{2}$, we investigated the correlation of these parameters using separate, and pooled, data from three randomized, placebo-controlled trials that have previously been published [16-18].

\section{Methods}

\section{Studies}

The objective of all three interventional studies was to evaluate the efficacy and safety of Oxalobacter formigenes, an anaerobic oxalate-degrading gut bacterium (Oxabact, OC3, or OC5, OxThera Intellectual Property AB, Sweden) [19-21].
$O$. formigenes is suggested to reduce the endogenous oxalate burden by promoting the removal of oxalate from the plasma into the intestine via passive and active flux processes $[22$, 23].

The current analysis was based on individual and pooled baseline data from three studies previously published which are briefly summarized as follows:

Study OC3-DB-01 (ClinicalTrials.gov Identifier: NCT00638703) was a phase $2 / 3$, double-blind, randomized, placebo-controlled, multicenter, international study conducted in 42 patients with $\mathrm{PH} 1$ and PH2 between 2007 and 2008. Patients received OC3 formulation (enteric-coated capsule) or placebo twice daily for 24 weeks [16].

Study OC3-DB-02 (ClinicalTrials.gov Identifier: NCT01037231) was a phase $2 / 3$, double-blind, randomized, placebo-controlled, multicenter, international study conducted in 36 patients with PH1 and PH2 between 2010 and 2011. Patients received OC3 formulation $500 \mathrm{mg}$ (reconstituted buffer solution) or placebo twice daily for 24 weeks [17].

Study OC5-DB-01 (ClinicalTrials.gov Identifier: NCT02012985) was a phase $1 / 2$, double-blind, randomized, placebo-controlled, multicenter, international study conducted in 28 patients with $\mathrm{PH} 1, \mathrm{PH} 2$ and $\mathrm{PH} 3$ between 2013 and 2015. Patients received OC5 formulation (enteric-coated capsule) or placebo twice daily for 8 weeks [18].

All studies were performed in accordance with good clinical practice (GCP) and the principles enshrined in the Declaration of Helsinki, and were approved by the relevant ethics committees. Patients were enrolled after providing written, informed consent and/or parental consent, depending on the age of the patient. The studies were designed, funded, and managed by OxThera Intellectual Property AB (Stockholm, Sweden).

\section{Inclusion/exclusion criteria}

Study OC3-DB-01 included patients aged $\geq 5$ years with urinary oxalate excretion $>1.0 \mathrm{mmol} / 1.73 \mathrm{~m}^{2} / 24 \mathrm{~h}$ and eGFR $\geq$ $50 \mathrm{~mL} / \mathrm{min} / 1.73 \mathrm{~m}^{2}$. Study OC3-DB-02 and study OC5-DB01 included patients aged $\geq 2$ years ( $\geq 5$ years in the UK) with urinary oxalate excretion $>1.0 \mathrm{mmol} / 1.73 \mathrm{~m}^{2} / 24 \mathrm{~h}$ and eGFR $\geq 40 \mathrm{~mL} / \mathrm{min} / 1.73 \mathrm{~m}^{2}$.

\section{Estimated glomerular filtration rate}

The eGFR equations used for the pediatric and adult populations, respectively, were Schwartz bedside 2009, eGFR = $0.413 \times$ (height $[\mathrm{cm}] /(\mathrm{SCr})$ (where $\mathrm{SCr}$ is serum creatinine) [ 24 ] a n d M D R D 2007 , e G F R = $175 \times(\mathrm{SCr})^{-1.154} \times(\text { age })^{-0.203} \times 1.212$ (if black) $\times 0.742$ (if female) [25]. 


\section{Plasma oxalate analysis}

Blood samples were obtained at baseline and processed for determination of Pox. Plasma oxalate was analyzed using the "free" Pox method in study OC3-DB-01 and using the "total" Pox method in Studies OC3-DB-02 and OC5-DB-01. Free Pox was measured by the oxalate oxidase assay $[26,27]$ in which ultrafiltration of plasma removes proteins and circulating crystals, leaving only soluble oxalate for analysis. Normal values for free Pox with this assay are in the range of 1$3 \mu \mathrm{mol} / \mathrm{L}$. Samples for free Pox determination were analyzed at the Mayo Central Laboratory for Clinical Trials, Rochester, USA.

Total Pox was measured using an isotope dilution mass spectrometric assay (gas chromatography with mass selective detection) [28]. The samples were first acidified to hydrolyze proteins, release bound $\mathrm{CaOx}$ and to dissolve $\mathrm{CaOx}$ crystals, and Pox was then extracted with ethylacetate prior to analysis. Normal values for total Pox with this assay are in the range of $\leq 7 \mu \mathrm{mol} / \mathrm{L}$. Samples for total Pox determination were analyzed at the Academic Medical Center, University of Amsterdam, Netherlands.

\section{Statistical methods}

Analyses of studies OC3-DB-01, OC3-DB-02, and OC5-DB01 at baseline are presented individually. Pooled baseline data were also evaluated for Studies OC3-DB-02 and OC5-DB-01. Data from study OC3-DB-01 were not included in the pooled analysis because the study used a different Pox assay, which could have affected the correlation. Six patients were identified as having participated in more than one of the three trials; their data was therefore only included once, in study OC3DB-02, when pooling data.

Descriptive statistics are provided as mean, median, standard deviation (SD), and range for continuous variables; frequency and percentage are provided for categorical variables. All values used were collected at baseline before study drug administration. Patients were classified into CKD stages, according to the National Kidney Foundation guidelines, based on their baseline eGFR; study inclusion criteria permitted recruitment of patients with CKD stages 1-3.

The association of eGFR with Pox was examined along with characteristics of normal distribution and linear relationship [29]. Based on indications of Pox and eGFR data being nonnormally distributed, the nonparametric Spearman's rank correlation coefficient was primarily used providing an indication of the monotone association between eGFR and Pox. The Pearson's product-moment correlation coefficient, measuring the strength of the linear relationship between eGFR and Pox, and the coefficient of determination $R^{2}$ (amount of variance in eGFR explained by Pox) were calculated as supplementary analyses. Scatterplots including the linear regression line, corresponding regression equation and, for the pooled data, a nonparametric smooth curve (local polynomial regression) were generated, capturing the general data trend based on local estimated scatterplot smoothing (LOESS) procedure fitting [30]. The data included in our analyses satisfied the independence assumption when evaluating the regression and the Pearson's product-moment linear correlation coefficient. Results were not adjusted for multiple testing. All statistical analyses were conducted using SAS software (version 9.4; SAS Institute, Cary, NC, USA).

\section{Results}

\section{Study population}

A total of 106 patients were included: 42 patients from study OC3-DB-01, 36 patients from study OC3-DB-02, and 28 patients from study OC5-DB-01 (Table 1). Primary hyperoxaluria type 1 accounted for $>83 \%$ of diagnoses in all three studies; only one patient had a diagnosis of PH3. Median time since diagnosis was 5.7-9.0 years across studies. Most patients in each study had CKD stages 1 or 2: 36 patients $(85.7 \%)$ in study OC3-DB-01, 29 patients $(80.5 \%)$ in study OC3-DB-02, and 27 patients (85.7\%) in study OC5-DB-01. No major differences in sex and age were found between studies, and the majority of all study patients were recorded as Caucasian or not African American.

\section{Estimated glomerular filtration rate, plasma oxalate, and urinary oxalate}

There were no notable differences in median (range) eGFR reported across studies at baseline $\left(80.3 \mathrm{~mL} / \mathrm{min} / 1.73 \mathrm{~m}^{2}\right.$ (42.4-160.0) in study OC3-DB-01, $80.8 \mathrm{~mL} / \mathrm{min} / 1.73 \mathrm{~m}^{2}$ (36.1-141.4) in study OC3-DB-02 and $81.3 \mathrm{~mL} / \mathrm{min} /$ $1.73 \mathrm{~m}^{2}(34.3-159.9)$ in study OC5-DB-02). Median (range) Pox was lower in study OC3-DB-01 at $6.5 \mu \mathrm{mol} / \mathrm{L}(1.6-25.2)$ than in studies OC3-DB-02 and OC5-DB-01 $(9.9 \mu \mathrm{mol} / \mathrm{L}$ (4.5-35.0) and $12.5 \mu \mathrm{mol} / \mathrm{L}$ (4.6-43.1), respectively) at baseline. The overall range for individual Pox values was 1.6$43.1 \mu \mathrm{mol} / \mathrm{L}$ for the populations across all three studies. There were no differences in baseline urinary oxalate between the three studies; median (range) baseline urinary oxalate was $1.59 \mathrm{mmol} / 1.73 \mathrm{~m}^{2} / 24 \mathrm{~h}(1.02-3.13)$ in study OC3-DB-01, $1.79 \mathrm{mmol} / 1.73 \mathrm{~m}^{2} / 24 \mathrm{~h}(1.05-2.75)$ in study OC3-DB-02, and $1.62 \mathrm{mmol} / 1.73 \mathrm{~m}^{2} / 24 \mathrm{~h}(0.90-3.08)$ in study OC5-DB01 . Similarly, there were no differences in baseline urinary oxalate per creatinine ratio values between the three studies; median (range) baseline urinary oxalate per creatinine ratio was $160.3 \mathrm{mmol} / \mathrm{mol}(65.3-451.8)$ in study OC3-DB-01, $178.8 \mathrm{mmol} / \mathrm{mol}(80.0-415.0)$ in study OC3-DB-02, and $146.7 \mathrm{mmol} / \mathrm{mol}(55.5-466.7)$ in study OC5-DB-01. 
Table 1 Demographic and baseline characteristics

\begin{tabular}{|c|c|c|c|}
\hline & OC3-DB-01 $(N=42)$ & OC3-DB-02 $(N=36)$ & OC5-DB-01 $(N=28)$ \\
\hline \multicolumn{4}{|l|}{ Age (years) } \\
\hline Mean & 14.1 & 18.4 & 14.5 \\
\hline SD & 6.7 & 14.5 & 5.6 \\
\hline Median & 13.0 & 15.0 & 14.5 \\
\hline Min, Max & 6,39 & 3,62 & 3,27 \\
\hline \multicolumn{4}{|l|}{$\operatorname{Sex}(n(\%))$} \\
\hline Male & $19(45.2)$ & $19(52.8)$ & $15(53.6)$ \\
\hline Female & $23(54.8)$ & $17(47.2)$ & $13(46.4)$ \\
\hline \multicolumn{4}{|l|}{ Race $(n(\%))$} \\
\hline Caucasian & $35(83.3)$ & $35(97.2)$ & N/A \\
\hline Asian & $5(11.9)$ & N/A & N/A \\
\hline Other & $2(4.8)$ & $1(2.8)$ & N/A \\
\hline African American/Black & 0 & N/A & $1(3.6)$ \\
\hline Not African American & N/A & N/A & $27(96.4)$ \\
\hline \multicolumn{4}{|l|}{ PH type $(n(\%))$} \\
\hline Type 1 & $35(83.3)$ & $31(86.1)$ & $26(92.9)$ \\
\hline Type 2 & $7(16.7)$ & $5(13.9)$ & $1(3.6)$ \\
\hline Type 3 & N/A & N/A & $1(3.6)$ \\
\hline \multicolumn{4}{|l|}{ Time since diagnosis (years) ${ }^{\mathrm{a}}$} \\
\hline Mean & 8.5 & 9.5 & 9.0 \\
\hline SD & 5.9 & 10.0 & 5.3 \\
\hline Median & 9.0 & 5.7 & 8.3 \\
\hline Min, Max & $-0.1^{\mathrm{b}}, 23.4$ & $-0.1^{\mathrm{c}}, 41.6$ & $1.3,19.6$ \\
\hline \multicolumn{4}{|l|}{ CKD stage $(\mathrm{n}(\%))$} \\
\hline Stage 1 & $15(35.7)$ & $16(44.4)$ & $12(42.9)$ \\
\hline Stage 2 & $21(50.0)$ & $13(36.1)$ & $12(42.9)$ \\
\hline Stage $3 a$ & $4(9.5)$ & $3(8.3)$ & $3(10.7)$ \\
\hline Stage $3 b$ & $2(4.8)$ & $4(11.1)$ & $1(3.6)$ \\
\hline \multicolumn{4}{|l|}{$\mathrm{eGFR}\left(\mathrm{mL} / \mathrm{min} / 1.73 \mathrm{~m}^{2}\right)$} \\
\hline Mean & 83.4 & 83.8 & 86.6 \\
\hline SD & 24.8 & 27.5 & 30.5 \\
\hline Median & 80.3 & 80.8 & 81.3 \\
\hline Min, Max & $42.4,160.0$ & $36.1,141.4$ & $34.3,159.9$ \\
\hline \multicolumn{4}{|l|}{$\operatorname{Pox}(\mu \mathrm{mol} / \mathrm{L})^{\mathrm{d}}$} \\
\hline Mean & $7.5^{\mathrm{e}}$ & 12.1 & $14.7^{\mathrm{f}}$ \\
\hline SD & $5.1^{\mathrm{e}}$ & 6.6 & $9.9^{\mathrm{f}}$ \\
\hline Median & $6.5^{\mathrm{e}}$ & 9.9 & $12.5^{\mathrm{f}}$ \\
\hline Min, Max & $1.6,25.2^{\mathrm{e}}$ & $4.5,35.0$ & $4.6,43.1^{\mathrm{f}}$ \\
\hline \multicolumn{4}{|c|}{ Urinary oxalate $\left(\mathrm{mmol} / 1.73 \mathrm{~m}^{2} / 24 \mathrm{~h}\right)^{\mathrm{g}}$} \\
\hline Mean & 1.77 & 1.80 & 1.74 \\
\hline SD & 0.59 & 0.50 & 0.59 \\
\hline Median & 1.59 & 1.79 & 1.62 \\
\hline Min, Max & $1.02,3.13$ & $1.05,2.75$ & $0.90,3.08$ \\
\hline \multicolumn{4}{|c|}{ Urinary oxalate per creatinine ratio $(\mathrm{mmol} / \mathrm{mol})$} \\
\hline Mean & 184.4 & 179.6 & 174.0 \\
\hline SD & 87.2 & 70.0 & 94.5 \\
\hline Median & 160.3 & 178.8 & 146.7 \\
\hline Min, Max & $65.3,451.8$ & $80.0,415.0$ & $55.5,466.7$ \\
\hline
\end{tabular}

eGFR Estimated glomerular filtration rate; Max maximum; Min minimum; Pox plasma oxalate; SD standard deviation

${ }^{\text {a }}$ Date of written informed consent minus date of diagnosis

${ }^{\mathrm{b}}$ One subject provided written informed consent but was kept in screening until a definitive primary hyperoxaluria diagnosis was made

${ }^{\mathrm{c}}$ One subject had a primary hyperoxaluria diagnosis two days after randomization; the patient was previously diagnosed before randomization, however, the official diagnosis was lost between physicians

${ }^{\mathrm{d}}$ Free plasma oxalate was calculated in study OC3-DB-01, while total plasma oxalate was calculated in studies OC3-DB-02 and OC5-DB-01

${ }^{\mathrm{e}} N=40$

${ }^{\mathrm{f}} N=27$

${ }^{\mathrm{g}}$ Urinary oxalate was calculated without centrifuging in study OC5-DB-01 


\section{Correlation between plasma oxalate and estimated glomerular filtration rate}

Scatter plots are presented displaying the relationship between Pox and eGFR in study OC3-DB-01 (Fig. 1a), study OC3DB-02 (Fig. 1b), and study OC5-DB-01 (Fig. 1c). A moderate and statistically significant inverse correlation between eGFR and Pox was observed $(p<0.05)$ in each of the three studies (Table 2), with Spearman's correlation coefficients of -0.44 in study OC3-DB-01, -0.55 in study OC3-DB-02, and -0.51 in study OC5-DB-01. Pooled data analyses from studies OC3DB-02 and OC5-DB-01 (Fig. 2) also resulted in a statistically significant inverse correlation $(p=0.0001)$ between Pox and eGFR when analyzing linear regression, with a Spearman's correlation coefficient of -0.49 . A statistically significant nonlinear relationship was also observed when local polynomial regression was used (Fig. 2; smooth line); the curve was steeper at eGFR values less than approximately $100 \mathrm{~mL} / \mathrm{min} /$ $1.73 \mathrm{~m}^{2}$ than those above.

\section{Discussion}

Our analysis of baseline (predose) Pox and eGFR data from three randomized, placebo-controlled trials demonstrates a statistically significant inverse moderate correlation between eGFR and Pox in PH patients with CKD stages $1-3 b$. The correlation between Pox and eGFR has generally been thought to occur only in patients with advanced stages of CKD (stages 3b-5) [14, 31]. Previous reports [1] suggested that as a result of the better ability of kidneys to excrete excess oxalate at higher eGFR levels, Pox and eGFR may not correlate well in early stages of CKD. In contrast, the correlation of eGFR and Pox in the population reported in this analysis indicates that elevations in Pox are observed before substantial loss in kidney function has occurred. Thus, Pox may be a factor in the development of kidney damage, and could possibly be considered as a leading indicator in itself. Data from the pooled analysis suggests that the relationship between Pox and eGFR is nonlinear across the range of eGFR values assessed; the observed curve steepens when eGFR approaches and falls below $100 \mathrm{~mL} / \mathrm{min} / 1.73 \mathrm{~m}^{2}$.

Table 2 Correlation between Pox and eGFR

\begin{tabular}{lll}
\hline Study & Correlation $^{\mathrm{a}}$ & $p$ value \\
\hline OC3-DB-01 & -0.44 & 0.0042 \\
OC3-DB-02 & -0.55 & 0.0005 \\
OC5-DB-01 & -0.51 & 0.0064 \\
Pooled: OC3-DB-02 and OC5-DB-01 & -0.49 & 0.0001 \\
\hline
\end{tabular}

${ }^{\text {a }}$ Spearman's rank correlation coefficients are presented
In the general population, Pox concentrations are often too low to quantify, however our data suggest that in patients with $\mathrm{PH}$, Pox is quantifiable even when eGFR is preserved, supporting its potential use as a biomarker [13, 14, 27]. The observed correlation between Pox and eGFR at higher eGFR ranges may support the utilization of Pox as a clinical trial endpoint facilitating determination of efficacy in future PH intervention studies in patients with CKD stages $1-3 \mathrm{~b}$. This conclusion is echoed by a recent consensus paper which supported the use of elevated Pox levels in patients with compromised kidney function (CKD stages $3 \mathrm{~b}-5$ ) as a likely surrogate endpoint for treatment efficacy, as well as proposing Pox as a causal factor for nephrocalcinosis and kidney stones in patients with preserved kidney function (CKD stages 1-3a) [10].

This is the first analysis to demonstrate a consistent correlation between Pox and eGFR using data from several randomized, placebo-controlled studies; an appropriate study design is paramount to acquiring high quality data, especially when the data are necessary to drive treatment advancement in rare diseases. While registry studies have provided significant information in $\mathrm{PH}$, and remain a valuable tool in analyzing characteristics in patient populations, methodologies used are of importance in interpretation of results. For example, Pox concentrations in registry studies can be influenced by differences in methods used for sample handling, sample preparation, and analysis of Pox samples. High intra- and interlaboratory variability in reported values can therefore occur due to this lack of assay standardization, ultimately affecting diagnostic value and evaluation of treatment efficacy [32]. A study comparing Pox analysis methods used in patients with $\mathrm{PH}$ noted poor agreement in Pox reporting between six laboratories [33]. In the current analysis, we pooled data only from studies OC3-DB02 and OC5-DB-01 because both used the same instructions for sample handling, the same Pox assay, and analyses were conducted at the same laboratory. One further advantage of using clinical trial data in our analyses is that the study protocols defined clearly the eligibility criteria, permitted concomitant medications and specific sampling time points, all of which can be a source of variability in registry data.

In addition to study design and the assays used for determination of Pox concentrations, there are additional confounding factors that can influence the relationship between Pox and eGFR, such as eGFR equations and intra- and individual patient differences. Other limitations could include the statistical methodology applied. Using primarily the nonparametric Spearman's rank correlation coefficient in our study allowed us to assess the baseline data appropriately in the three studies we describe; this complied with assumption of data points independence, and normal distribution/linearity were not violated.

Though there is substantial intersubject variability in the progression and severity of disease, the effects of $\mathrm{PH}$ can be devastating. Improvements in diagnostic procedures and 
Fig. 1 Plasma oxalate (Pox) vs. estimated glomerular filtration rate (eGFR). Individual values of Pox and eGFR in patients with both values recorded at baseline in a study OC3-DB-01 $(\mathrm{n}=40)$, b study OC3-DB-02 $(n=36)$, and c study OC5-DB-01 ( $n=27)$.

Baseline Pox was measured using the free Pox method (study OC3DB-01) or total Pox method (studies OC3-DB-02 and OC5DB-01). Pox = plasma oxalate. eGFR $=$ estimated glomerular filtration rate
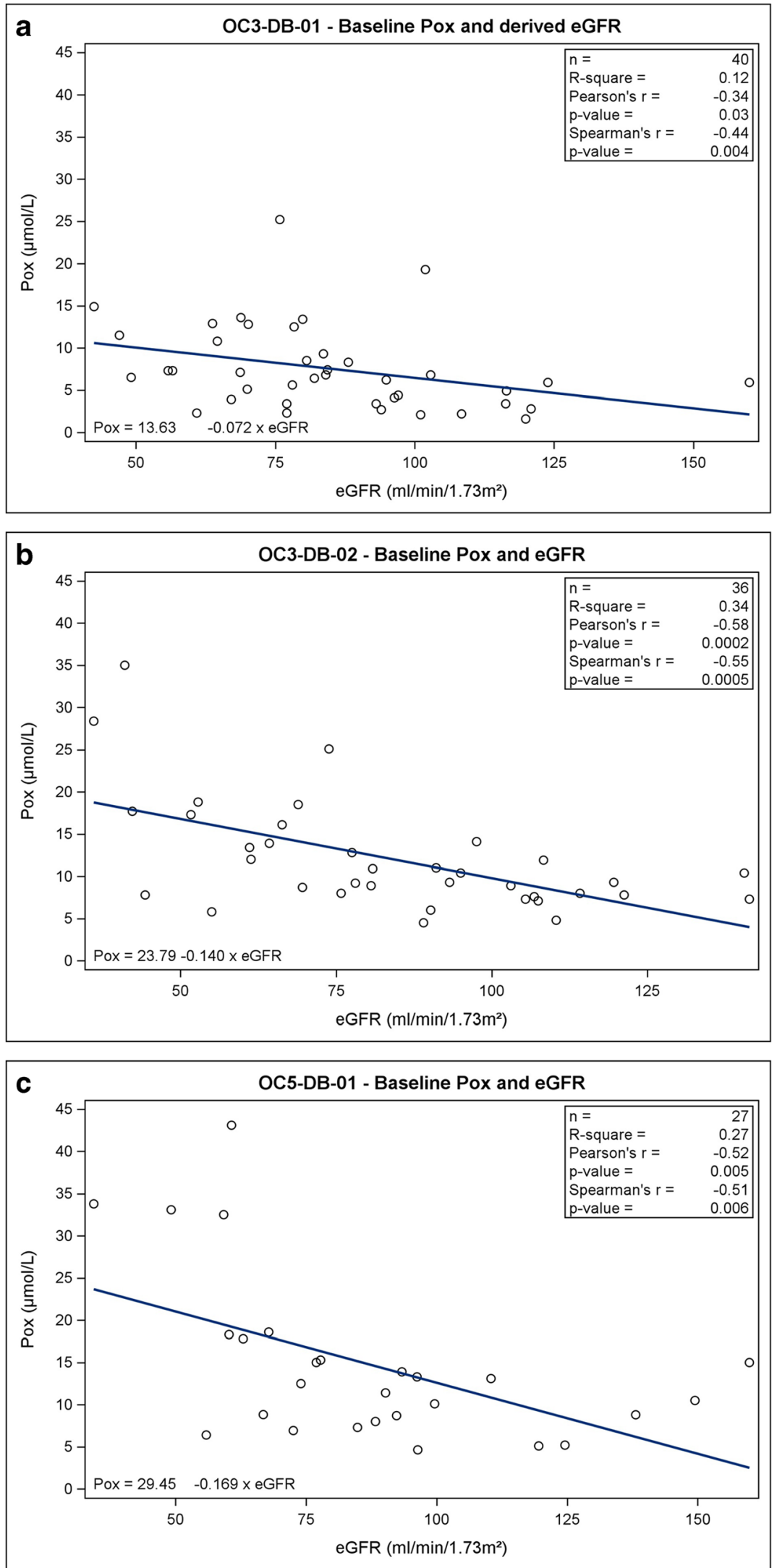
Fig. 2 Pooled plasma oxalate (Pox) vs. estimated glomerular filtration rate (eGFR): Studies OC3-DB-02 and OC5-DB-01. Pooled individual values of Pox and eGFR in patients with both values recorded at baseline $(n=$ 57) in studies OC3-DB-02 and OC5-DB-01. Six patients identified as participating in both studies were included only once, in study OC3-DB-02, when pooling data. Baseline Pox was measured using the total Pox method. Pox $=$ plasma oxalate. eGFR = estimated glomerular filtration rate

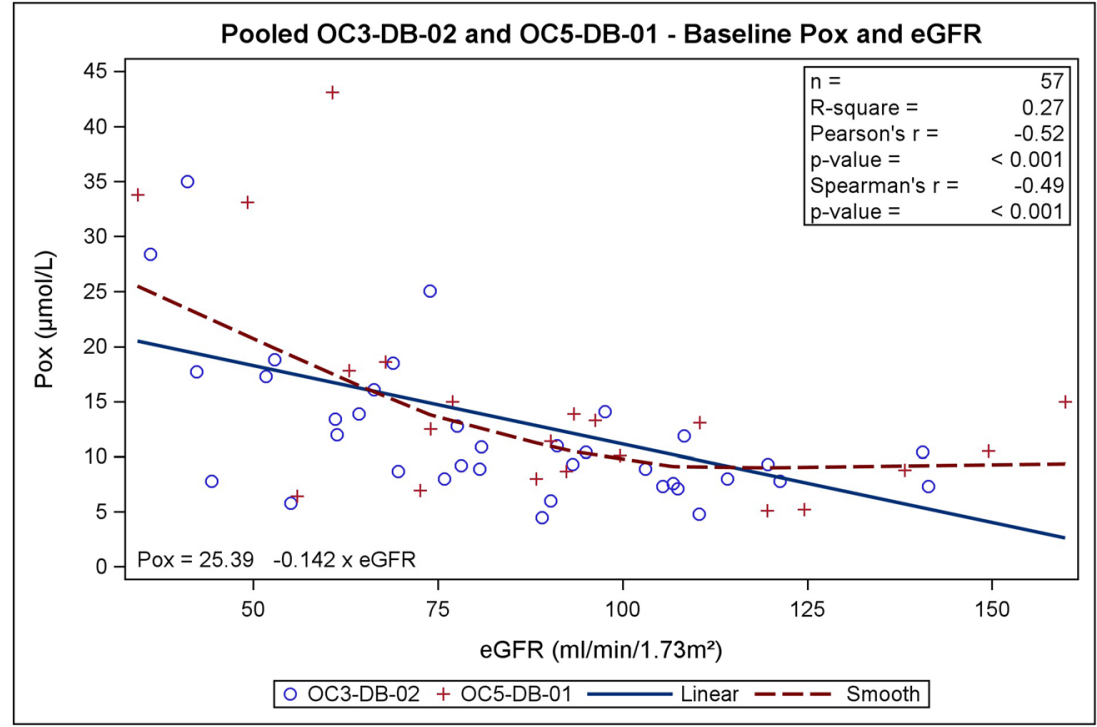

disease management have increased median survival of patients with $\mathrm{PH} 1$ - cohort studies suggest a median kidney survival of between 24 and 33 years [11, 34, 35] — yet there is only a single, recently approved drug therapy for PH1 and no approved drug therapies for $\mathrm{PH} 2$ and $\mathrm{PH} 3$. Our analysis has certain limitations, chiefly that the low numbers of patients with a diagnosis of $\mathrm{PH} 2$ or $\mathrm{PH} 3$ did not permit sufficient statistical power to analyze the results by PH type. The majority of patients were Caucasian or not African American, highlighting the need for further research into patients of other racial and ethnic groups. Kidney function was estimated from the Schwartz and MDRD equations for practical reasons instead of formal measurement of GFR with, for instance, iohexol. Finally, the cross-sectional design of our study does not permit conclusions regarding a causal relationship between Pox concentration and change in eGFR. Despite these limitations, we demonstrate a statistically significant inverse correlation of moderate strength between Pox and eGFR in PH1 populations with CKD stages $1-3 b$. Other studies note the plausibility of Pox being on the causal pathway for kidney damage, that higher Pox concentrations can be a risk factor for kidney failure [10], and suggest that Pox concentration could potentially serve as a prognostic indicator of kidney function decline [13]. While our data cannot fully support these conclusions, the observed correlation at a single time point leads us to speculate that Pox concentration may at least serve as a marker for kidney function. This represents an area for further research.

In conclusion, our data from the baseline analysis of three randomized, placebo-controlled trials showed a statistically significant inverse correlation between eGFR and Pox in patients with $\mathrm{PH}$ across a broad range of kidney function (eGFR $>40 \mathrm{~mL} / \mathrm{min} / 1.73 \mathrm{~m}^{2}$ (CKD stage 1-3b)), and demonstrate that Pox can be elevated at kidney function traditionally regarded as normal. Prospective clinical studies are ongoing to evaluate change in Pox and its relationship to clinical outcome. Extensive research over the years has greatly advanced the development of desperately needed treatments for $\mathrm{PH}$, and our study contributes to the growing body of evidence that could aid development of new strategies to assess clinical benefit in patients with $\mathrm{PH}$.

Supplementary Information The online version contains supplementary material available at https://doi.org/10.1007/s00467-020-04894-9.

Acknowledgements Placebo-controlled clinical studies were sponsored by OxThera Intellectual Property AB. Medical writing support was provided by Madeleine Parker of Niche Science and Technology Ltd., Richmond-upon-Thames, Surrey, UK; this was paid for by OxThera Intellectual Property AB, Stockholm, Sweden.

Funding The studies were designed, funded, and managed by OxThera Intellectual Property AB (Stockholm, Sweden).

Data availability The authors confirm that the data supporting the findings of this study are available within the article.

\section{Compliance with ethical standards}

Conflict of interest Ana Banos, Bastian Dehmel, and Elisabeth Lindner are employed by OxThera Intellectual Property AB, Stockholm, Sweden.

Ethics approval All procedures performed in studies involving human participants were in accordance with the ethical standards of the institutional and/or national research committee and with the 1964 Helsinki Declaration and its later amendments or comparable ethical standards. The studies were approved by the local authorities and local Ethics Committees.

Consent to participate Informed consent was obtained from all individual participants included in the study. For minor patients, informed consent was obtained from the parents/caregivers, and an assent was obtained from the patient.

Consent for publication Not applicable. 
Code availability Not applicable.Supplementary Information The online version contains supplementary material available at https://doi. org/10.1007/s00467-020-04894-9.

Open Access This article is licensed under a Creative Commons Attribution 4.0 International License, which permits use, sharing, adaptation, distribution and reproduction in any medium or format, as long as you give appropriate credit to the original author(s) and the source, provide a link to the Creative Commons licence, and indicate if changes were made. The images or other third party material in this article are included in the article's Creative Commons licence, unless indicated otherwise in a credit line to the material. If material is not included in the article's Creative Commons licence and your intended use is not permitted by statutory regulation or exceeds the permitted use, you will need to obtain permission directly from the copyright holder. To view a copy of this licence, visit http://creativecommons.org/licenses/by/4.0/.

\section{References}

1. Cochat P, Rumsby G (2013) Primary hyperoxaluria. N Engl J Med 369:649-658. https://doi.org/10.1056/NEJMra1301564

2. Hoppe B (2012) An update on primary hyperoxaluria. Nat Rev Nephrol 8:467-475. https://doi.org/10.1038/nrneph.2012.113

3. Harambat J, Fargue S, Bacchetta J, Acquaviva C, Cochat P (2011) Primary hyperoxaluria. Int J Nephrol 2011:864580. https://doi.org/ $10.4061 / 2011 / 864580$

4. Fargue A, Milliner DS, Knight J, Olson JB, Lowther WT, Holmes RP (2018) Hydroxyproline metabolism and oxalate synthesis in primary hyperoxaluria. J Am Soc Nephrol 29:1615-1623. https:// doi.org/10.1681/ASN.2017040390

5. Brzica H, Breljak D, Burckhardt BC, Burckhardt G, Sabolic I (2013) Oxalate: from the environment to kidney stones. Arh Hig Rada Toksikol 64:609-630. https://doi.org/10.2478/10004-125464-2013-2428

6. Lorenz EC, Michet CJ, Milliner DS, Lieske JC (2013) Update on oxalate crystal disease. Curr Rheumatol Rep 15:340. https://doi. org/10.1007/s11926-013-0340-4

7. Worcester E, Evan A, Coe F, Lingeman JE, Krambeck A, Sommers A, Philips CL, Milliner D (2013) A test of the hypothesis that oxalate secretion produces proximal tubule crystallization in primary hyperoxaluria type 1. Am J Physiol Renal Physiol 305:F1574F1584. https://doi.org/10.1152/ajprenal.00382.2013

8. Ermer T, Eckardt KU, Aronson PS, Knauf F (2016) Oxalate, inflammasome, and progression of kidney disease. Curr Opin Nephrol Hypertens 25:363-371. https://doi.org/10.1097/MNH. 0000000000000229

9. Beck BB, Hoyer-Kuhn H, Göbel H, Habbig S, Hoppe B (2013) Hyperoxaluria and systemic oxalosis: an update on current therapy and future directions. Expert Opin Investig Drugs 22:117-129. https://doi.org/10.1517/13543784.2013.741587

10. Milliner DS, McGregor TL, Thompson A, Dehmel B, Knight J, Rosskamp R, Blank M, Yang S, Fargue S, Rumsby G, Groothoff J, Allain M, West M, Hollander K, Lowther WT, Lieske JC (2020) Endpoints for clinical trials in primary hyperoxaluria. Clin J Am Soc Nephrol. https://doi.org/10.2215/CJN.13821119

11. Hopp K, Cogal AG, Bergstralh EJ, Barbara SM, Olson JB, Meek AM, Lieske JC, Milliner DS, Harris PC (2015) Phenotypegenotype correlations and estimated carrier frequencies of primary hyperoxaluria. J Am Soc Nephrol 26:2559-2570. https://doi.org/ 10.1681/ASN.2014070698
12. Lieske JC, Monico CG, Holmes WS, Bergstralh EJ, Slezak JM, Roglinger AL, Olson JB, Milliner DS (2005) International registry for primary hyperoxaluria. Am J Nephrol 25:290-296. https://doi. org/10.1159/000086360

13. Shah RJ, Vaughan LE, Enders FT, Milliner DS, Lieske JC (2020) Plasma oxalate as a predictor of kidney function decline in a primary hyperoxaluria cohort. Int J Mol Sci 21:E3608. https://doi.org/10. 3390/ijms21103608

14. Perinpam M, Enders FT, Mara KC, Vaughan LE, Ramila AM, Voskoboev N, Milliner DS, Lieske JC (2017) Plasma oxalate in relation to eGFR in subjects with primary hyperoxaluria, enteric hyperoxaluria and urinary stone disease. Clin Biochem 50:10141019. https://doi.org/10.1016/j.clinbiochem.2017.07.017

15. Hillebrand P, Hoppe B (2020) Plasma oxalate levels in primary hyperoxaluria type I show significant intra-individual variation and do not correlate with kidney function. Pediatr Nephrol 35: 1227-1233. https://doi.org/10.1007/s00467-020-04531-5

16. Hoppe B, Groothoff JW, Hulton SA, Cochat P, Niaudet P, Kemper MJ, Deschênes G, Unwin R, Milliner D (2011) Efficacy and safety of Oxalobacter formigenes to reduce urinary oxalate in primary hyperoxaluria. Nephrol Dial Transplant 26:3609-3615. https:// doi.org/10.1093/ndt/gfr107

17. Milliner D, Hoppe B, Groothoff J (2018) A randomised phase II/III study to evaluate the efficacy and safety of orally administered Oxalobacter formigenes to treat primary hyperoxaluria. Urolithiasis 46:313-323. https://doi.org/10.1007/s00240-0170998-6

18. Hoppe B, Niaudet P, Salomon R, Harambat J, Hulton SA, Hoff WV, Moochhala SH, Dechênes G, Lindner E, Sjögren A, Cochat P (2017) A randomised phase I/II trial to evaluate the efficacy and safety of orally administered Oxalobacter formigenes to treat primary hyperoxaluria. Pediatr Nephrol 32:781-790. https://doi.org/ 10.1007/s00467-016-3553-8

19. Dawson KA, Allison MJ, Hartman PA (1980) Isolation and some characteristics of anaerobic oxalate degrading bacteria from the rumen. Appl Environ Microbiol 40:833-839

20. Allison MJ, Dawson KA, Mayberry WR, Foss JG (1985) Oxalobacter formigenes gen. Nov., sp. nov.: oxalate-degrading anaerobes that inhabit the gastrointestinal tract. Arch Microbiol 141:1-7. https://doi.org/10.1007/BF00446731

21. Kelly JP, Curhan GC, Cave DR, Anderson TE, Kaufman DW (2011) Factors related to colonization with Oxalobacter formigenes in U.S. adults. J Endourol 25:673-679. https://doi.org/10.1089/end. 2010.0462

22. Knauf F, Lo N, Jiang Z, Robertson WG, Van Itallie CM, Anderson JM, Aronson PS (2011) Net intestinal transport of oxalate reflects passive absorption and SLC26A6-mediated secretion. J Am Soc Nephrol 22:2247-2255. https://doi.org/10.1681/ASN.2011040433

23. Hatch M, Freel RW (2013) A human strain of Oxalobacter (HC-1) promotes enteric oxalate secretion in the small intestine of mice and reduces urinary oxalate excretion. Urolithiasis 41:379-384. https:// doi.org/10.1007/s00240-013-0601-8

24. Schwartz GJ, Muñoz A, Schneider MF, Robert MH, Frederick K, Bradley WA, Furth SL (2009) New equations to estimate GFR in children with CKD. J Am Soc Nephrol 20:629-637. https://doi.org/ 10.1681/ASN.2008030287

25. Levey AS, Coresh J, Greene T, Marsh J, Stevens LA, Kusek JW, Van Lente F (2007) Expressing the modification of diet in renal disease study equation for estimating glomerular filtration rate with standardized serum creatinine values. Clin Chem 53:766-772. https://doi.org/10.1373/clinchem.2006.077180

26. Hoppe B, Kemper MJ, Hvizd MG, Sailer DE, Langman CB (1998) Simultaneous determination of oxalate, citrate and sulfate in children's plasma with ion chromatography. Kidney Int 53:1348-1352. https://doi.org/10.1046/j.1523-1755.1998.00891.x 
27. Ladwig PM, Liedtke RR, Larson TS, Lieske JC (2005) Sensitive spectrophotometric assay for plasma oxalate. Clin Chem 51:23772380. https://doi.org/10.1373/clinchem.2005.054353

28. Wolthers BG, Hayer M (1982) The determination of oxalic acid in plasma and urine by means of capillary gas chromatography. Clin Chim Acta 120:87-102. https://doi.org/10.1016/0009-8981(82) 90080-8

29. Chen PY, Popovich PM (2002) Correlation: parametric and nonparametric measures. Sage Publications, Thousand Oaks

30. Cleveland WS, Grosse E (1991) Computational methods for local regression. Stat Comput 1:47-62

31. da Silva SL, Cochat P, Rech DL, Parant F, de Souza VC, Dubourg L (2018) Association between glomerular filtration rate (measured by high-performance liquid chromatography with iohexol) and plasma oxalate. J Bras Nefrol 40:73-76. https://doi.org/10.1590/ 1678-4685-JBN-3743

32. Rumsby G, Hulton SA (2019) From pathogenesis to novel therapies in primary hyperoxaluria. Expert Opinion on Orphan Drugs 7:5766. https://doi.org/10.1080/21678707.2019.1571905

33. Stokes F, Acquaviva-Bourdain C, Hoppe B, Lieske JC, Lindner E, Toulson G, Frédéric M, Rumsby G (2020) Plasma oxalate: comparison of methodologies. Urolithiasis. https://doi.org/10. 1007/s00240-020-01197-4

34. Harambat J, Fargue S, Acquaviva C, Gagnadoux MF, Janssen F, Liutkus A, Mourani C, Macher MA, Abramowicz D, Legendre C, Durrbach A, Tsimaratos M, Nivet H, Girardin E, Schott AM, Rolland MO, Cochat P (2010) Genotype-phenotype correlation in primary hyperoxaluria type 1: the p.Gly170Arg AGXT mutation is associated with a better outcome. Kidney Int 77:443-449. https:// doi.org/10.1038/ki.2009.435

35. Mandrile G, van Woerden CS, Berchialla P, Bodo B, AcquavivaBourdain C, Hulton SA, Rumsby G, OxalEurope Consortium (2014) Data from a large European study indicate that the outcome of primary hyperoxaluria type 1 correlates with the AGXT mutation type. Kidney Int 86:1197-1204. https://doi.org/10.1038/ki.2014. 222

Publisher's note Springer Nature remains neutral with regard to jurisdictional claims in published maps and institutional affiliations. 